\title{
Beak and feather disease virus: biology and resultant disease
}

Subir Sarker, ${ }^{1 *}$ Jade K Forwood, Shane R Raidal

\begin{abstract}
The beak and feather disease virus (BFDV) causes psittacine beak and feather disease, an often chronic and fatal disease in psittacine birds. The virus most commonly infects psittacine birds, but is also capable of infecting nonpsittacine bird species in Australasia. The virus induces an immunosuppressive condition with chronic symmetrical irreversible loss of feather, as well as beak and claw deformities eventually leading to death. No specific treatment is currently commercially available for infected birds; however, a combination of quarantine and hygiene control, diagnostic testing and enhancing flock adaptive immunity is recommended to provide the most effective and sustainable control. Recent structural determination of BFDV capsid protein provides insights into the different assemblies that can be formed from one of the smallest known DNA viruses.
\end{abstract}

Keywords: Parrots, BFDV structure, circovirus

\section{History}

Psittacine beak and feather disease (PBFD) was first described in the early 1980 s and has become recognised as the dominant viral pathogen of psittacine birds worldwide. In wild red-rumped grass parakeets (Psephotus haematonotus), a case of feather loss syndrome that was highly suggestive of PBFD was first recorded in South Australia in 1907. ${ }^{[1]}$ The virus causing PBFD was initially designated as psittacine circovirus but has since been renamed beak and feather disease virus (BFDV).

\section{Structure of beak and feather disease virus}

The beak and feather disease virus (BFDV) is currently considered a member of the family Circoviridae. Like other circoviruses, BFDV possesses a small, circular single-stranded DNA (ssDNA) genome (approximately 2.0 $\mathrm{kb}$ in length) that is encapsidated into a non-enveloped, spherical icosahedral virion. ${ }^{[2]}$ In order to replicate its genome, BFDV needs to invade the nucleus to access the transcriptional machinery of the host cell. The replication of BFDV is known to occur in numerous tissues,

\footnotetext{
${ }^{1}$ La Trobe University

*Author correspondence: s.sarker@latrobe.edu.au

ORCID: 0000-0002-2685-8377

0000-0003-3267-9997

0000-0001-7917-8976

Licensed under: CC-BY

Received 27-01-2020; accepted 20-09-2020
}

including skin, liver, gastrointestinal tract, and bursa of Fabricius; ${ }^{[3][4]}$ while the capsid antigen of BFDV is found in the spleen, thymus, thyroid, parathyroid and bone marrow. ${ }^{[5]}$ However, the distinction between viral entry and replication in a host cell remains unclear in the absence of confirmation in suitable cell culture. Viral attachment and entry into host cells may not necessarily lead to viral replication, and consequently not all cells containing viral particles may contribute to the disease progression. However, it is thought that the BFDV encodes proteins that actively transport the viral genome into the nucleus, as well as factors that direct the precursor DNA exit to the cytoplasm, where it causes large globular intracytoplasmic paracrystalline arrays (Figure 1). ${ }^{[2]}$

The BFDV genome is bi-directionally transcribed and encodes at least two major proteins: a replication initiation protein (rep) expressed from the virion strand and a capsid protein (cap) expressed from the complementary strand. A recent study conducted by Sarker et al. used a combination of X-ray crystallography, cryo-electron microscopy and atomic force microscopy to investigate the functionality of cap and its interaction with a range of host and viral proteins. They confirmed that the cap protein forms virus-like particles (VLPs) of $\sim 17$ $\mathrm{nm}$ (mature form) and a smaller assembly of $\sim 10 \mathrm{~nm}$ (immature form) (Figure 2). Furthermore, this study demonstrated that assembly of these two VLPs is regulated by single-stranded DNA (ssDNA), and that they 


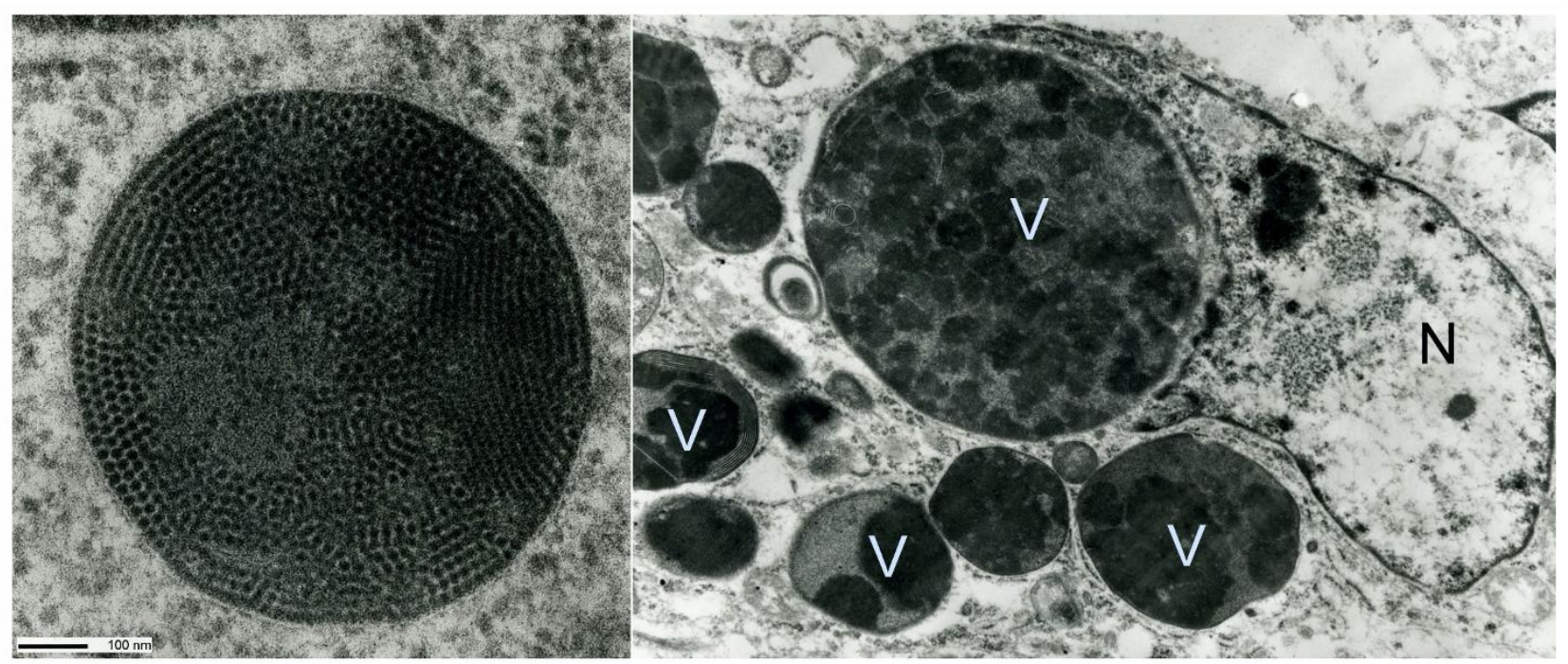

Figure 1 | Transmission electron micrograph of BFDV infected cell on the right demonstrating how the nucleus (N) is relatively sparse, with large crystalline arrays of mature virus particles preferentially forming intracytoplasmic inclusions (V) shown at higher magnification on the left.

Sarker et al, CC-BY 4.0

provide a structural basis of capsid assembly around single-stranded DNA. ${ }^{[2]}$

\section{Host range and transmission}

BFDV infection was thought to be restricted to within Psittaciformes, but evidence of host switching among distantly-related Australian avian species was recently demonstrated in the rainbow bee-eater (Merops ornatus) ${ }_{1}^{[6]}$ powerful owl (Ninox strenua) $)^{[7]}$ and finches. ${ }^{[8]}$ A large number of other non-psittacine birds are likely susceptible to sporadic spill-over infection, ${ }^{[9]}$ and there is unpublished evidence of BFDV-associated feather disease in the laughing kookaburra (Daceolo novaeguineae), columbids, corvids and raptors including the wedge-tailed eagle (Aquila audax), white-breasted sea eagle (Haliaetus leucogaster), peregrine falcon (Falco peregrinus) and whistling kite (Haliastur sphenurus). ${ }^{[10]}$ However, the actual mechanism of this host-switch event in raptors and other species is not well understood. Presumably, it occurs in raptors and other birds following predation and/or opportunistic feeding upon the tissues or excretions of BFDV-affected parrots and cockatoos. Knemidokoptes mites have recently been shown to concentrate BFDV within their faeces ${ }^{[11]}$ which raises the possibility of ectoparasites such as hippoboscid flies acting as fomites and vectors of transmission particularly to insectivorous bird species such as the rainbow bee-eater. Interestingly, while interseasonal nest hollow sharing may promote the circulation of novel BFDV genotypes in psittacine populations, species such as raptors, which retain nest hollows over many seasons, may not have sufficient intraspecific transmission frequencies to permit permanent host switching. ${ }^{[10]}$

Beak and feather disease virus is the dominant viral pathogen of Psittaciformes in Australasia, where it has been present for at least 10 million years, ${ }^{[10]}$ and Australia has been identified as the most likely origin of the

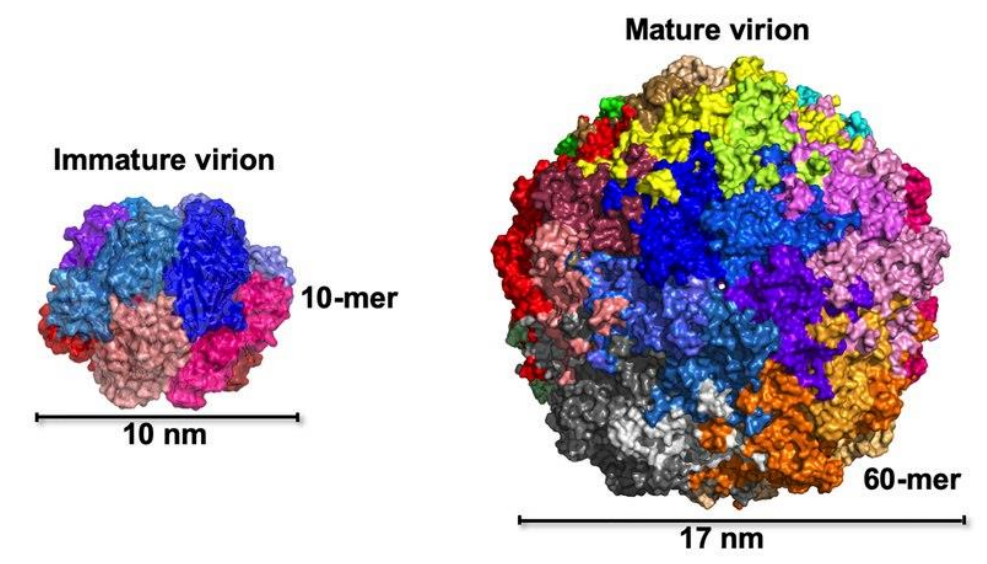

Figure 2 | Structural characterisation of two BFDV capsid virions. X-ray crystal structures allow modelling of the two particles to $1.9 \AA$ (10 nm-immature virions, left), and $2.5 \AA$ ( $60 \mathrm{~nm}$-mature virions, right). The smaller particle is composed of 10 capsid molecules arranged as two interlocking discs, with each disc containing five capsid molecules. The larger VLP consists of 12 pentamers arranged with $\mathrm{T}=1$ icosahedral symmetry. ${ }^{[2]}$

Sarker et al, CC-BY 4.0 
virus. ${ }^{[12]}$ The richness of psittacine avifauna in this region has produced a mixture of potential hosts for the pathogens, resulting in competing forces of virus coevolution, spill-over infection and virus host-switches within parrots, cockatoos and lorikeets. Recent evidence has shown that all threatened and endangered Australian psittacine bird species can be infected by BFDV genotypes from any other closely- or distantlyrelated host reservoir species. ${ }^{[13][14]}$ Currently, more than 78 psittacine bird species globally have been reported to be infected by BFDV, including at least 38 of the 50 Australian native parrot species both in captivity and the wild, and over 25 non-psittacine bird species. ${ }^{[9][15][16][17][128][10][199[7][6][20]}$

Transmission is thought to include both horizontal and vertical modalities. In wild bird populations, transmission of infection most likely occurs within nest hollows by oral or intracloacal ingestion of the virus possibly sourced from feather dust, crop secretions, or faeces. ${ }^{[21][4]}$ Although there has been debate in the literature concerning the role of vertical transmission of avian circovirus, BFDV is suspected to be transmitted vertically because viral DNA can be found in embryos from infected hens. ${ }^{[22]}$ However, this could simply be the result of non-replicative transfer of viral DNA into the yolk of embryonated eggs. Further investigations are required in this regard.

\section{Disease}

The beak and feather disease virus is the cause of psittacine beak and feather disease (PBFD), which is recognised as an infectious threat for endangered Australian psittacine birds and constitutes a well-characterised threat to a wide variety of psittacine and non-psittacine bird species globally. [9][23][17][128][10][24][25][14][199][7][6][26] The disease presents as an immunosuppressive condition with chronic symmetrical irreversible loss of feathers as well as beak and claw deformities, eventually leading to death (Figure 3). ${ }^{[5][27][28][29][30]}$ It can also be expressed peracutely, ranging from sudden death, particularly in neonates, ${ }^{\left[3^{13}\right]}$ to an acute form in nestling and fledglings, characterised by feather dystrophy, diarrhoea, weakness and depression ultimately leading to death within 1-2 weeks. ${ }^{\left[{ }^{[1]}\right.}$ In some species with green plumage, the presence of scattered yellow contour feathers throughout the plumage is often the first clinical signs of PBFD. In juvenile crimson rosellas (Platycercus elegans) early signs include subtle feather dystrophy, segmentally retained feather sheaths and feather loss around the nares. $^{[10]}$
Secondary viral, fungal, bacterial, or parasitic infections often occur as a result of diminished immunity caused by a PBFD viral infection. Clinical signs in addition to those mentioned above, including elevated white blood cell counts, are generally due to secondary infections and may not be directly related to PBFD virus infections. Furthermore, not all infected birds develop feather lesions. Some respond with an appropriate immune response and recover. There is also considerable evidence, at least in lovebirds and orange-bellied parrots, of persistent infections in otherwise normal-appearing individuals. It is likely that these subclinically infected birds, in addition to ones with feather dysplasia, are responsible for shedding into the environment and infection of susceptible birds.

\section{Impacts}

PBFD caused by BFDV has the potential to become a significant threat to all species of wild parrots and to modern aviculture, due to international legal and illegal bird trade ${ }^{[18]} \mathrm{A}$ large number of psittacine and non-psittacine bird species globally are currently affected by BFDV both in captivity and in the wild, and the disease has the potential to disrupt vital ecosystem processes and services. ${ }^{[9][16][18][7][6]} A$ recent study has shown the importance of an accurate evaluation of avian diseases in wild populations, since invasive parrots may introduce BFDV without showing any visually detectable clinical signs. ${ }^{\left[{ }^{[2]}\right]}$ PBFD was one of the first diseases to be recognised as threatening under the Endangered Species Protection Act 1992 (ESP Act). ${ }^{[13]}$ The Environment Protection and Biodiversity Conservation Act 1999 developed a threat abatement plan (TAP) with two broad goals: ensure that PBFD does not escalate the threatened species status of affected birds; and minimise the likelihood of PBFD becoming a key threatening process

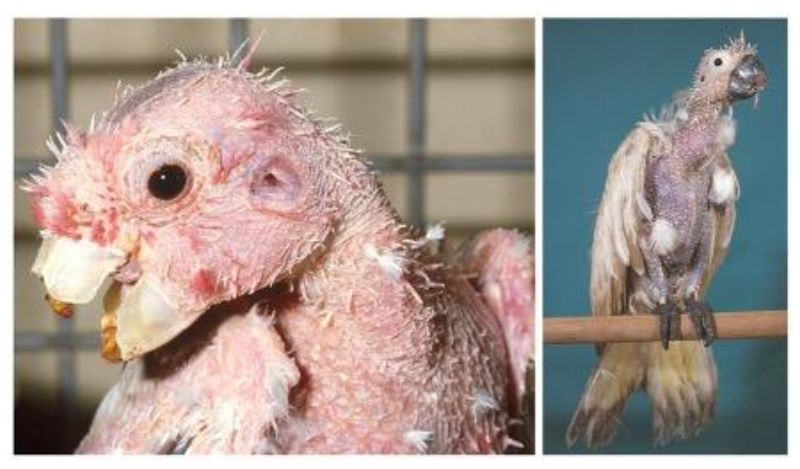

Figure 3 | Galah (left) with chronic PBFD showing feather loss and beak deformities, and a sulphur-crested cockatoo (right) infected with BFDV displaying gross clinical signs of feather loss.

Shane R. Raidal, Charles Sturt University, CC-BY 4.0 
(KTP) for other psittacine species. ${ }^{[16]}$ In June 2015, a ministerial review concluded that the goals of the TAP had not been met due to considerable deficits in knowledge concerning PBFD. ${ }^{[33]}$

\section{Diagnosis}

Various approaches have been developed and employed for the diagnosis of BFDV. These include histology, electron microscopy, haemagglutination, ${ }^{[34][35]} \mathrm{im}$ munohistochemistry, ${ }_{1}^{[36]}$ in situ hybridisation, ${ }^{[37]}$ polymerase chain reaction $(P C R),{ }^{[38]}$ duplex shuttle $P C R_{1}{ }^{[39]}$ real-time $P C R_{1}{ }^{[40]} P C R$ followed by high-resolution melting curve analysis, ${ }^{[15][20]}$ and swarm primer-applied loop-mediated isothermal amplification (sLAMP). ${ }^{[4]]}$ The serological detection of anti-BFDV antibodies has been conducted by haemagglutination inhibition [34][42] and Enzyme-Linked Immunosorbent Assay (ELISA) ${ }^{[36]}$. So far, the standard PCR-based assay has been used most frequently (>49\%) to screen BFDV between 1984 and July $20155^{[18]} \mathrm{A}$ recently developed SLAMP assay may serve as a rapid, sensitive, and specific diagnostic field test for the detection of BFDV in clinical samples. ${ }^{[41]}$

\section{Treatment and control}

Currently no commercially viable specific treatment for birds affected with chronic PBFD exists. Epidemiological studies have shown a high seroprevalence in wild and captive flocks, indicating that infection does not always lead to the development of feather lesions. Testing regimes currently rely on a combination of viral DNA testing using PCR methods, and excreted antigen detection in feather dander using haemagglutination assay (HA) alongside serology using haemagglutination inhibition (HI). The results can identify subclinical birds that are infected but not excreting virus, while also serving to monitor for an antibody response in those birds which have been exposed to infection. Depending on the stage of infection, the PCR-positive or -negative status of infected birds can wax and wane while they develop $\mathrm{HI}$ antibody. In some species, a positive $\mathrm{HI}$ antibody result is strong evidence of freedom from infection and disease. Culling of infected birds is normally performed in infected captive or commercial flocks. There is an ongoing need to develop a vaccine to combat BFDV infection. It has been recommended that a combination of quarantine and hygiene control, diagnostic testing and enhancing flock adaptive immunity should be practised to provide the most effective and sustainable control. ${ }^{[10]}$

\section{Acknowledgements}

Dr Sarker is the recipient of an Australian Research Council Discovery Early Career Researcher Award (grant number DE200100367) funded by Australian Government. The Australian Government had no role in study design, data collection and analysis, decision to publish, or preparation of the manuscript.

Competing interests: none declared.

\section{References}

1. Ashby, E. (1907). "Parrakeets moulting". Emu 6 (4): 193-194. doi:10.1071/MUgo6192f.

2. Sarker, S.; Terrón, M.C.; Khandokar, Y.; Aragão, D.; Hardy, J.M.; Radjainia, M.; Jiménez-Zaragoza,, M.; de Pablo, P.J. et al. (2016). "Structural insights into the assembly and regulation of distinct viral capsid complexes". Nature Communications 7: 13014. doi:10.1038/ncomms13014.

3. Raidal, S.R.; Cross, G.M. (1995). "Acute necrotizing hepatitis caused by experimental infection with psittacine beak and feather disease virus". Journal of Avian Medicine and Surgery 9 (1): 36-40.

4. Wylie, S.L.; Pass, D.A. (1987). "Experimental reproduction of psittacine beak and feather disease french moult". Avian Pathology 16 (2): 269-281. doi:10.1080/03079458708436374.

5. Latimer, K.S.; Rakich, P.M.; Kircher, I.M.; Ritchie, B.W.; Niagro, F.D.; Steffens, W.L.; Lukert, P.D. (1990). "Extracutaneous viral inclusions in psittacine beak and feather disease". Journal of Veterinary Diagnostic Investigation 2 (3): 204-207. doi:10.1177/104063879000200309.

6. Sarker, S.; Moylan, K.G.; Ghorashi, S.A.; Forwood, J.K.; Peters, A.; Raidal, S.R. (2015). "Evidence of a deep viral host switch event with beak and feather disease virus infection in rainbow bee-eaters (Merops ornatus)". Scientific Reports 5: 14511. doi:10.1038/srep14511.

7. Sarker, S.; Lloyd, C.; Forwood, J.; Raidal, S.R. (2016). "Forensic genetic evidence of beak and feather disease virus infection in a Powerful Owl, Ninox strenua". Emu 116 (1): 71-74. doi:10.1071/MU15063.

8. Circella, E.; Legretto, M.; Pugliese, N.; Caroli, A.; Bozzo, G.; Accogli, G.; Lavazza, A.; Camarda, A. (2014). "Psittacine Beak and Feather Diseaselike Illness in Gouldian Finches (Chloebia gouldiae)". Avian Diseases 58 (3): 482-487. doi:10.1637/10745-121113case.1.

9. Amery-Gale, J.; Marenda, M.S.; Owens, J.; Eden, P.A.; Browning, G.F.; Devlin, J.M. (2017). "A high prevalence of beak and feather disease virus in non-psittacine Australian birds". Journal of Medical Microbiology 66: 10051013. doi:10.1099/jmm.0.000516.

10. Raidal, S.R.; Peters, A. (2018). "Psittacine beak and feather disease: ecology and implications for conservation". Emu 118 (1): 80-93. doi:10.1080/01584197.2017.1387029.

11. Portas, T.; Jackson, B.; Das, S.; Shamsi, S.; Raidal, S. R. (2017). "Beak and feather disease virus carriage by Knemidocoptes pilae in a sulphur-crested cockatoo (Cacatua galerita)". Australian Veterinary Journal 95 (12): 486489. doi:10.1111/avj.12649.

12. Harkins, G.W.; Martin, D.P.; Christoffels, A.; Varsani, A. (2014). "Towards inferring the global movement of beak and feather disease virus". Virology 450-451: 24-33. doi:10.1016/j.virol.2013.11.033.

13. Raidal, S.R.; Sarker, S.; Peters, A. (2015). "Review of psittacine beak and feather disease and its effect on Australian endangered species". Australian Veterinary Journal 93 (12): 466-470. doi:10.1111/avj.12388.

14. Sarker, S.; Forwood, J.K.; Ghorashi, S.A.; Peters, A.; Raidal, S.R. (2015). "Beak and feather disease virus genotypes in Australian parrots reveal flexible host-switching". Australian Veterinary Journal 93 (12): 471-475. doi:10.1111/avj.12389.

15. , S.; Sarker, S.; Ghorashi, S.A.; Forwood, J.K.; Raidal, S.R. (2016). "A comparison of $P C R$ assays for beak and feather disease virus and high resolution melt (HRM) curve analysis of replicase associated protein and capsid genes". Journal of Virological Methods 237: 47-57. doi:10.1016/j.jviromet.2016.08.015.

16. Department of the Environment and Heritage (2005). Threat Abatement Plan for Psittacine Beak and Feather Disease affecting endangered psittacine 
species.Canberra, ACT 2601 (PDF) (Report). Department of the Environment and Heritage, Commonwealth of Australia.

17. Eastwood, J.R.; Berg, M.L.; Ribot, R.F.; Raidal, S.R.; Buchanan, K.L.; Walder, K.R.; Bennett, A.T. (2014). "Phylogenetic analysis of beak and feather disease virus across a host ring-species complex". Proceedings of the $\mathrm{Na}$ tional Academy of Sciences 111 (39): 14153-14158. doi:10.1073/pnas.1403255111.

18. Fogell, D.J.; Martin, R.O.; Groombridge, J.J. (2016). "Beak and feather disease virus in wild and captive parrots: an analysis of geographic and taxonomic distribution and methodological trends". Archives of Virology 161 (8): 2059-2074. doi:10.1007/s00705-016-2871-2.

19. Sarker, S.; Ghorashi, S.A.; Forwood, J.K.; Bent, J.S.; Peters, A.; Raidal, S.R. (2014). "Phylogeny of beak and feather disease virus in cockatoos demonstrates host generalism and multiple-variant infections within Psittaciformes". Virology 460-461: 72-82. doi:10.1016/j.virol.2014.04.021.

20. Sarker, S.; Ghorashi, S.A.; Forwood, J.K.; Raidal, S.R. (2014). "Rapid genotyping of beak and feather disease virus using high-resolution DNA melt curve analysis". Journal of Virological Methods 208: 47-55. doi:10.1016/j.jviromet.2014.07.031.

21. Ritchie, B.W.; Niagro, F.D.; Latimer, K.S.; Steffens, W.L.; Pesti, D.; Ancona, J.; Lukert, P.D. (1991). "Routes and prevalence of shedding of psittacine beak and feather disease virus". American Journal Veterinary Research 52 (11): 1804-1809

22. Rahaus, M.; Desloges, N.; Probst, S.; Loebbert, B.; Lantermann, W.; Wolff, M.H. (2008). "Detection of beak and feather disease virus DNA in embryonated eggs of psittacine birds". Veterinarni Medicina 53 (1): 53-58. doi:10.17221/1932-VETMED.

23. Das, S.; Sarker, S.; Peters, A.; Ghorashi, S.A.; Phalen, D.; Forwood, J.K.; Raidal, S.R. (2016). "Evolution of circoviruses in lorikeets lags behind its hosts". Molecular Phylogenetics and Evolution 100: 281-291. doi:10.1016/j.ympev.2016.04.024.

24. Sarker, S.; Das, S.; Ghorashi, S.A. (2014a). "Molecular characterization of genome sequences of beak and feather disease virus from the Australian Twenty-Eight Parrot (Barnardius zonarius semitorquatus)". Genome Announcements 2 (6): e01255-14. doi:10.1128/genomeA.01255-14.

25. Sarker, S.; Forwood, J.K.; Ghorashi, S.A.; McLelland, D.; Peters, A.; Raidal, S.R. (2014). "Whole-genome sequence characterization of a beak and feather disease virus in a wild regent parrot (Polytelis anthopeplus monarchoides)". Genome Announcements 2 (1): 01243-13. doi:10.1128/genomeA.01243-13.

26. Varsani, A.; Regnard, G.L.; Bragg, R.; Hitzeroth, I.I.; Rybicki, E.P. (2011). "Global genetic diversity and geographical and host-species distribution of beak and feather disease virus isolates". Journal of General Virology 92 (4): 752-767. doi:10.1099/vir.0.028126-0.

27. Pass, D.A.; Perry, R.A. (1984). "The pathology of psittacine beak and feather disease". Australian Veterinary Journal 61 (3): 69-74. doi:10.1111/j.1751-0813.1984.tb15520.x.

28. Raidal, S.R.; McElnea, C.L.; Cross, G.M. (1993). "Seroprevalence of psittacine beak and feather disease in wild psittacine birds in New South Wales". Australian Veterinary Journal 70 (4): 137-139. doi:10.1111/j.17510813.1993.tbo6105.x.

29. Ritchie, B.W.; Niagro, F.D.; Latimer, K.S.; Lukert, P.D.; Steffens, W.L., III; Rakich, P.M.; Pritchard, N. (1990). "Ultrastructural, protein composition, and antigenic comparison of psittacine beak and feather disease virus purified from four genera of psittacine birds". Journal of Wildlife Diseases 26 (2): 196-203. doi:10.7589/0090-3558-26.2.196.

30. Ritchie, B.W.; Niagro, F.D.; Lukert, P.D.; Steffens, W.L., III; Latimer, K.S. (1989). "Characterization of a new virus from cockatoos with psittacine beak and feather disease". Virology 171 (1): 83-88. doi:10.1016/00426822(89)90513-8.

31. Ritchie, B.W. (1995). "Circoviridae". Avian viruses: Function and control. Lake Worth, FL: Wingers Publishing Inc. pp. 223-252. ISBN og63699636.

32. Morinha, F.; Carrete, M.; Tella, J.L.; Blanco, G. (2020). "High Prevalence of Novel Beak and Feather Disease Virus in Sympatric Invasive Parakeets Introduced to Spain From Asia and South America". Diversity 12 (5). doi:10.3390/d12050192.

33. Psittacine Beak and Feather Disease and other identified Threats to Australian threatened Parrots (PDF) (Report). Department of Environment. 2015. Archived from the original (PDF) on August 28, 2020.

34. Khalesi, B.; Bonne, N.; Stewart, M.; Sharp, M.; Raidal, S.R. (2005). "A comparison of haemagglutination, haemagglutination inhibition and PCR for the detection of psittacine beak and feather disease virus infection and a comparison of isolates obtained from loriids". Journal of General Virology 86 (11): 3039-3046. doi:10.1099/vir.0.81275-0.

35. Raidal, S.R.; Cross, M.G. (1994). "The haemagglutination spectrum of psittacine beak and feather disease virus". Avian Pathology 23 (4): 621-630. doi:10.1080/03079459408419032.

36. Shearer, P.L.; Bonne, N.; Clark, P.; Sharp, M.; Raidal, S.R. (2008). "Development and applications of a monoclonal antibody to a recombinant beak and feather disease virus (BFDV) capsid protein". Journal of Virological Methods 147 (2): 206-212. doi:10.1016/j.jviromet.2007.08.029.

37. Ramis, A.; Latimer, K.S.; Niagro, F.D.; Campagnoli, R.P.; Ritchie, B.W.; Pesti, D. (1994). "Diagnosis of psittacine beak and feather disease (PBFD) viral infection, avian polyomavirus infection, adenovirus infection and herpesvirus infection in psittacine tissues using DNA in situ hybridization". Avian Pathology 23 (4): 643-657. doi:10.1080/03079459408419034.

38. Ypelaar, I.; Bassami, M.R.; Wilcox, G.E.; Raidal, S.R. (1999). "A universal polymerase chain reaction for the detection of psittacine beak and feather disease virus". Veterinary Microbiology 68 (1-2): 141-148. doi:10.1016/S0378-1135(99)00070-X.

39. Ogawa, H.; Yamaguchi, T.; Fukushi, H. (2005). "Duplex shuttle PCR for differential diagnosis of budgerigar fledgling disease and psittacine beak and feather disease". Microbiology and Immunology 49 (3): 227-237. doi:10.1111/j.1348-0421.2005.tb03724.x.

40. Shearer, P.L.; Sharp, M.; Bonne, N.; Clark, P.; Raidal, S.R. (2009). "A quantitative, real-time polymerase chain reaction assay for beak and feather disease virus". Journal of Virological Methods 159 (1): 98-104. doi:10.1016/j.jviromet.2009.03.009.

41. Chae, H.-G.; Lim, D.-R.; Kim, H.-R.; Park, M.-J.; Park, C.-K. (2020). "An advanced loop-mediated isothermal amplification assay for the rapid detection of beak and feather disease virus in psittacine birds". Journal of Virological Methods 277: 113819. doi:10.1016/j.jviromet.2020.113819.

42. Raidal, S.R.; Sabine, M.; Cross, G.M. (1993). "Laboratory diagnosis of psittacine beak and feather disease by haemagglutination and haemagglutination inhibition". Australian Veterinary Journal 70 (4): 133-137. doi:10.1111/j.1751-0813.1993.tbo6104.x. 